\title{
ИСПОЛЬЗОВАНИЕ ПЕРЕДОВЫХ ТЕХНОЛОГИЙ ДЛЯ НАНОМЕДИЦИНЫ: ПОЛУЧЕНИЕ МНОГОФУНКЦИОНАЛЬНЫХ «ВОЛШЕБНЫХ ПУЛЬ»
}

\author{
К. Мартина, Л. Серпе, Р. Кавалли, Д. Кравотто 凶 \\ Кафедра фармацевтических технологий, \\ Центр наноструктурированных интерфейсов и поверхностей, Туринский университет, Турин, Италия
}

\begin{abstract}
Недавние достижения в области нанотехнологии, в том числе современные методы, позволяющие усовершенствовать способы приготовления лекарственных средств, открыли новые горизонты в наномедицине, связанные с разработкой наноразмерных средств доставки лекарственных препаратов и целых комплексов. Последнее десятилетие большое внимание уделяется использованию нанопереносчиков - усилия исследователей направлены не столько на разработку новых препаратов, сколько на поиск способов целевой доставки терапевтических и/или диагностических агентов. В работе рассмотрены трансдисциплинарный подход к получению наноматериалов, нанокомплексов, нановезикул и перспективы их применения в биологии и тераностике. Особое внимание уделено получению нанопузырьков, стимулчувствительных наночастиц (НЧ) и наносистем с привитым циклодекстрином при нестандартных условиях, таких как действие ультразвука (УЗ) и микроволнового излучения. Помимо использования в процессе приготовления НЧ, УЗ можно так же эффективно применять для активации чувствительных нановезикул и НЧ.
\end{abstract}

Ключевые слова: наночастицы, нанопузырьки, стимулчувствительный, ультразвук, микроволновое излучение

Финансирование: авторы признательны администрации Туринского университета за их финансовую поддержку (Ricerca Locale 2017).

$\triangle$ Для корреспонденции: Джанкарло Кравотто

ул. Р. Giuria, д. 9, Турин, Италия, 10125; giancarlo.cravotto@unito.it

Статья получена: 26.06.2018 Статья принята к печати: 30.08.2018

DOI: $10.24075 / \mathrm{vrgmu} .2018 .082$

\section{ENABLING TECHNOLOGIES FOR THE PREPARATION OF MULTIFUNCTIONAL "BULLETS” FOR NANOMEDICINE}

Martina K, Serpe L, Cavalli R, Cravotto $G \bowtie$

Department of Drug Science \& Technology,

Centre for Nanostructured Interfaces and Surfaces (NIS), University of Turin, Turin, Italy

\begin{abstract}
Recent advances in nanotechnology, including modern enabling techniques that can improve synthetic preparation and drug formulations, have opened up new frontiers in nanomedicine with the development of nanoscale carriers and assemblies. The use of delivery platforms has attracted attention over the past decade as researchers shift their focus away from the development of new drug candidates, and toward new means with which to deliver therapeutic and/or diagnostic agents. This work will explore a transdisciplinary approach for the production of a number of nanomaterials, nanocomplexes and nanobubbles and their application in a variety of potential biological and theranostic protocols. Particular attention will be paid to nanobubbles, stimuli responsive nanoparticles and cyclodextrin grafted nanosystems produced under non-conventional conditions, such as microwave and ultrasound irradiation. Besides nanoparticles preparation, ultrasound can also act as an enabling technology when activating sensitive nanobubbles and nanoparticles.
\end{abstract}

Keywords: nanoparticles, nanobubbles, stimuli responsive, ultrasound, microwave

Funding: the University of Turin is warmly acknowledged for their financial support (Ricerca Locale 2017).

$\triangle$ Correspondence should be addressed: Giancarlo Cravotto

Via P. Giuria 9, Turin, Italy, 10125; giancarlo.cravotto@unito.it

Received: 26.06.2018 Accepted: 30.08.2018

DOI: $10.24075 / \mathrm{brsmu} .2018 .082$

Наноматериалы могут быть получены практически из любого вещества; наряду с липофильными коллоидными наночастицами (НЧ), получаемыми из твердых липидов и фосфолипидов, возможно использование наноматериалов на основе углерода, натуральных и синтетических полимеров, кварца, металлов и оксидов металлов. В области бионанотехнологий наноматериалы используются для биомедицинского применения, в том числе целевой доставки лекарственных препаратов, контрастирующих веществ и биосенсоров. Многие свойства наноматериалов, которые делают их полезными, могут в то же время делать их токсичными для живых клеток. Благодаря большой площади поверхности наноматериалы более реактивны и легкотранспортируемы через экологические барьеры, клеточные мембраны и в организме в целом. Для максимального использования потенциала нанотехнологий необходим рациональный научный подход в вопросах нанотоксикологии и безопасности.

Среди способов приготовления Н4 существует множество различных подходов с использованием как общепринятых, так и нетрадиционных методик в твердых и жидких фазах [1]. Первостепенной задачей является получение НЧ, гомогенных по размеру и форме - для ее решения применяли ряд методов; в твердофазных протоколах без растворителей применялась механохимия, в то время как для синтеза в водных растворах использовали микроволновое излучение и ультразвук (УЗ). Микроволновое излучение как эффективный 
источник тепла позволяет получить большое количество высококачественных $\mathrm{H} Ч$ за короткие промежутки времени. Применение сонохимического облучения позволяет добиваться высокооднородного смешивания и уменьшения роста кристаллов, что также способствует улучшению динамики и увеличению скорости реакции. Данные подходы можно считать одним из наиболее эффективных средств для синтеза наноматериалов [2, 3].

Наработки в области сонохимического синтеза и синтеза с использованием микроволнового излучения можно эффективно применять для дериватизации наноматериалов на основе углерода, а также производства наноструктурированных олигомеров циклодекстрина (ЦД) и наноматериалов с привитым ЦД для применения в биомедицине. Показано, что производные ЦД способны удерживать молекулы лекарственных препаратов и контрастирующих веществ, и таким образом действовать как универсальные и эффективные переносчики и контрастирующие агенты для МРТ. Прививание ЦД на НЧ увеличивает их водорастворимость, поверхностную доступность и «акцептирующую» способность. Нанопузырьки, сферические структуры (ядро/оболочка), служат инновационными наноплатформами, на базе которых можно разрабатывать многофункциональные наноносители для целенаправленной визуализации и терапевтического применения. В области онкологии большое внимание привлекают стимулчувствительные наносистемы, повышающие эффективность действия противоопухолевых препаратов.

Использование стратегий нанодоставки может иметь ключевое значение для успешной терапии, поскольку делает возможным высвобождение лекарства «по требованию», а также персонализированный подход к лечению. В идеале речь может идти о концепции «нужное лекарство нужному человеку в нужный момент». Эта статья о текущем состоянии и перспективах использования «умных» наносистем доставки лекарственных средств, управляемых с помощью специсических внутренних (например, изменения редокс-потенциала) или внешних (например, свет, УЗ, магнитное поле) факторов.

\section{Наноматериалы на основе циклодекстрина или привитые циклодекстрином}

Использование нанотехнологий для доставки лекарственных средств открывает новые возможности целенаправленной доставки терапевтических препаратов к внутриклеточным целям и мониторингу целевых мест их доставки (тераностика), что может изменить облик фармацевтической и биотехнологической промышленности. Ключевая роль в достижении этих целей может принадлежать ЦД, отличающимся хорошей биологической совместимостью, способностью улучшать физико-химические свойства лекарственных средств (стабильность, растворимость, биодоступность) [4]. Наряду с другими синтетическими методами нетрадиционные технологии с использованием УЗ и микроволн нашли широкое применение в приготовлении новых и уже известных структур на основе ЦД, продемонстрировав хорошую эффективность и короткое время реакции.

При помощи УЗ был получен водорастворимый олигоЦД гетерононамер с целью использования его в качестве дендримерного мультиносителя с высокой принимающей способностью. Применимость его как контрастирующего агента для МРТ была продемонстрирована на релаксометрическом титровании Gd-комплексов, помещенных в дендримерные платформы, а также в успешных экспериментах по изучению жизнеспособности клеток и связывающей способности [5].

ЦД может быть эффективно привит на кварц при обычных и нетрадиционных условиях [6, 7] (рис. 1) способность этой гибридной системы абсорбировать органические молекулы в значительной степени изучена и опробована. Так, был исследован интересный пример двухпоровых НЧ кварца для эффективной комбинированной терапии рака с одновременным транспортом гена и противоопухолевого препарата. Положительно заряженная большая пора была загружена отрицательно заряженной малой интерферирующей PHК, а в меньшую пору был помещен доксорубицин, покрытый 1-Адамантантиолом и комплексом ЦД [8].

При помощи микроволнового излучения была успешно произведена дериватизация углеродных нанотрубок (SWCNT) с ЦД и контрастирующими веществами [9]. Эффективность микроволнового воздействия продемонстрирована также для получения оксида графена, привитого порфином [10].

Изучается способность ЦД присоединять или высвобождать лекарственные препараты применительно к магнитным НЧ. НЧ оксида железа и золота модисицировали присоединением к полиглицидилметакрилату, соединенному с ЦД и функционализированному этилендиамином с целью получения многофункциональной тераностической наноплатформы [11]. Магнитные НЧ под воздействием УЗ эффективно покрывались $\beta$-ЦД, что приводило к увеличению намагничивания, вероятно, в силу высокой степени кристаллизации полученной системы [12].

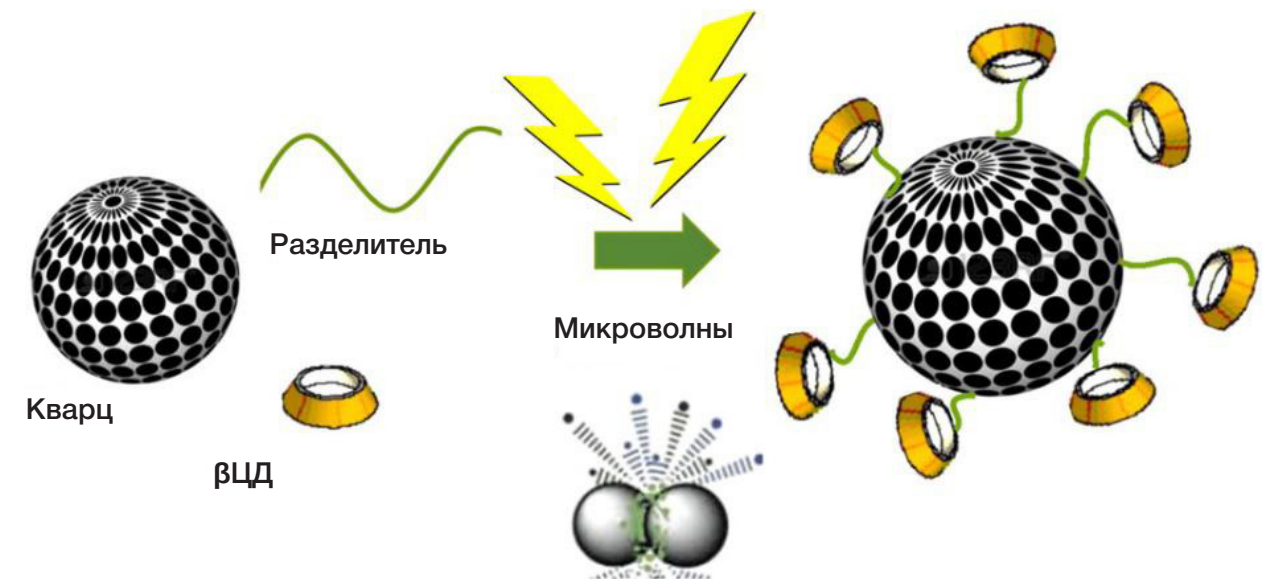

Рис. 1. Схема получения НЧ кварца, привитого циклодекстрином, в нестандартных условиях. (По данным: Martina K., Baricсо F. и др. [6].) 


\section{Нанопузырьки: универсальный инструмент для биомедицинского применения}

Нанопузырьки (нановезикулы) - еще одна ценная платформа для применения в визуализационных и терапевтических приложениях, разновидность «нанопуль», чувствительных к воздействию внешних физических факторов.

Нанопузырьки происходят из микропузырьков, которые в настоящее время используются в клинической практике в качестве контрастирующих агентов. Эта особенность определяет некоторые преимущества, такие как их выход из кровеносных сосудов в окружающие ткани, что повышает эффективность визуализации и целевой доставки. В частности, такая способность позволяет им в течение длительного времени накапливаться в тканях опухоли благодаря эффекту увеличенной проницаемости и задержания (enhanced permeability and retention, EPR). Кроме того, воздействием УЗ можно усилить акустические и таргетинговые свойства таких НЧ. Нанопузырьки можно использовать в качестве ядер терапевтической кавитации для УЗ-сонопорации, приводя к формированию временных пор в плазменных мембранах, а также изменению клеточной проницаемости [13].

Нанопузырьки могут быть описаны как сферические структуры, имеющие ядро и оболочку, заполненные газом или испаряющимся компонентом, таким как перфторуглероды, гексафторид серы, воздух или углекислый газ [14]. Ядро - внутреннее пространство, занимающее большую часть объема частицы. Компоненть ядра имеют принципиальное значение, так как могут влиять как на структурные, так и на функциональные характеристики. Использование нерастворимых в воде газов (например, перфторуглеродов) снижает скорость выхода газа от ядра в окружающее пространство, увеличивая тем самым срок жизни системы. Параметры сжимаемости газового ядра могут оказывать значительный эффект на объемные колебания системы из-за циклов сжатия/разрежения УЗ. Колебания объема пузырька могут усиливать эхо обратного рассеяния и способствовать высвобождению препарата, что может повышать эффективность диагностической визуализации и терапевтических применений соответственно.

Состав оболочки пузырьков определяет их жесткость и устойчивость к разрушению в поле давления УЗ, распознавание ретикулоэндотелиальной системой и биораспределение [15]. Оболочка обычно состоит из липидов (фосфолипидов, холестерина), полимеров (плюроников (Pluronic), полисахаридов, поли-D,L-лактидко-гликолидов (PLGA) или белков (альбумина).

Большое число исследований сосредоточено на ряде структур, среди которых нанопузырьки с ядром из перфторуглерода и полисахаридной оболочкой; их использование показало интересные результаты [16]. Это гибридные полимер-липидные системы, которые были разработаны для решения проблемы стабильности нанопузырьков и улучшения способности связывать лекарственные препараты. Присутствие полисахаридной оболочки делает возможным взаимодействие со специфическими лигандами.

$\mathrm{Ha}$ границе раздела гибридные системы содержат монослой фосфолипида, который может взаимодействовать с полиэлектролитами. Такая структура гибридной липид-полимерной системы разработана исходя из того, что монослои фоссфолипида могут адсорбировать заряженные полимеры, такие как полисахариды, посредством различных типов взаимодействия, включая электростатические и гидрофобные.

Были предприняты попытки создания нанопузырьков меньшего размера. Большинство из них включали технологические манипуляции с микропузырьками в процессе приготовления, например разделение по градиенту силы тяжести, физическая фильтрация или флотация. Другой подход к достижению этой цели изначальное формирование наноразмерных систем. В этом случае нанопузырьки получали главным образом с помощью обработки УЗ, эмульгирование с высоким сдвиговым усилием, тонкослойное испарение и механическое перемешивание; процедуры, которые также использовали для получения микропузырьков [13].

Нанопузырьки - универсальный инструмент для разработки наноносителей, управляемых извне, с контролируемым высвобождением действующего препарата и возможностями визуализации.

Следует отметить, что нанопузырьки демонстрируют высокую эффективность связывания (инкапсулирования) лекарственных препаратов и их пролонгированного высвобождения. В табл. 1 представлен список биологически активных молекул, которыми «загружали» перфторуглероднополисахаридные нанопузырьки, используя различные методы.

\section{Стимулчувствительные наносистемы}

Эффрективность лечения лекарственными препаратами в значительной степени зависит от того, насколько хорошо активный компонент достигает целевых органов и тканей. На пути к цели молекулы лекарства подвергаются ферментативному воздействию, возникают проблемы с доступом к целевой области, а также селективностью клеток. В связи с этим многообещающей является разработка систем адресной доставки лекарственных средств с использованием НЧ, показавших хорошие результаты как с пассивным, так и с активным нацеливанием. Кроме того, благодаря новым свойствам таких наносистем возможно увеличить бионакопление препарата в нужном месте.

В общепринятом смысле системы адресной доставки лекарственных средств с использованием НЧ обеспечивают выход препарата из кровеносного русла только в целевых местах, или органах-«мишенях», где происходит пассивное либо активное накопление НЧ. Пассивное аккумулирование происходит благодаря эффекту EPR, наблюдающемуся в патологических тканях. Так, в клетках опухоли накопление НЧ происходит намного быстрее, чем в других тканях и характеризуется неравномерным распределением и зависимостью от величины частиц. Активное накопление достигается за счет специфического взаимодействия наносистем с клеткамимишенями - благодаря наличию на поверхности НЧ моноклональных антител или биоконъюгатов [17].

Однако использование систем адресной доставки лекарственных средств с использованием НЧ часто сопровождается системными побочными эффектами, которые связаны с неспецисическим биораспределением и неконтролируемыми особенностями высвобождения препарата. На фармацевтическом рынке уже предложено несколько нанопрепаратов для лечения рака, в том числе Doxil $^{\circledast}$ и Abraxane ${ }^{\circledast}$, показавших улучшенные профили безопасности по сравнению с обычными препаратами 
(свободными). Однако отмечается, что бионакопление лекарства внутри опухоли все еще достаточно низкое, что приводит к недостаточному терапевтическому эффекту [18].

Для решения этих проблем идет поиск современных наносистем, способных обеспечить контролируемое в пространстве и времени прицельное высвобождение препарата. Совместные разработки в области наноматериалов и фармацевтических исследований прокладывают путь к развитию инновационных наноплатсорм, в частности для лечения онкологических заболеваний, когда наноматериалы могут играть решающую терапевтическую роль вместе с переносимым препаратом. Использование продуманных наносистем, чувствительных к воздействию внешних и внутренних факторов, может увеличить эффективность препарата и уменьшить побочные эффекты, что дает начало так называемым «умным» стимулчувствительным наносистемам [19].

Существующие стимулчувствительные наносистемы относятся к двум типам: а) способные реагировать на изменения в биологической среде и таким образом модулировать скорость высвобождения препарата по принципу системы обратной связи, зависящие от особенностей болезни (внутренние спусковые механизмы, такие как изменения $\mathrm{pH}$, редокс-потенциала, температуры и концентрации вещества); б) способные активироваться и высвобождать препарат под воздействием определенных внешних пусковых механизмов (свет, УЗ, температура, магнитное поле, высокоэнергетическое излучение) и таким образом действовать как системы разомкнутого контура, обеспечивающие импульсный выпуск лекарства.

Чувствительность К внутренним или внешним стимулам может быть достигнута использованием наноматериалов (главным образом, полимеров), несущих функциональные группы, способные менять их свойства в зависимости от интенсивности сигнала. Это приводит к изменению характеристик наносистемы, таких как способность высвобождать препарат. Изменения могут быть разного уровня сложности, но наносистему можно рассматривать как «умную» только при условии, что эти структурные изменения обратимы и пропорциональны интенсивности стимула. В случае опухолевых клеток такие требования могут быть лаконично определены как «2R2S», т. е. удержание препарата в процессе циркуляции в кровеносном русле - высвобождение препарата в опухоли (drug retention in blood circulations versus release in tumour; 2R) и неактивность в крови - активность в опухоли (stealthy in blood versus sticky in tumour; 2S) [18].

\section{1. Наносистемы, чувствительные к внутренним стимулам}

\section{1. Наночастицы с рН-зависимым ответом}

Классический пример стимул-зависимой наносистемы, реагирующей на внутренний сигнал, - работа $\mathrm{pH}$ чувствительного наноносителя, применяемого для целевого транспорта в плотные опухоли. Низкий уровень рН во внеклеточном матриксе, вызванный активностью гликолиза в опухолевой ткани, может выступать в качестве специфического стимула для наносистемы. Учитывая, что поверхностный потенциал напрямую связан с уровнем клеточного потребления, для целевой доставки в опухолевую ткань были предложены зарядиндуцируемые полимерные наносистемы. Положительно заряженные НЧ демонстрируют хорошую проникающую способность благодаря активному взаимодействию с клеточной мембраной. Более того, такие НЧ способны функционировать подобно «протонной губке», вызывая разрушение лизосом, способствуя доставке внутри объема цитоплазмы и провоцируя гибель раковой клетки [20].

Новый полимер на основе тетра-глюкозы, полученный Caldera c соавт., представляет собой цепь из циклической нигерозил-1-6-нигерозы (CNN). В результате кросс-связи тетра-глюкозы и пиромеллитового диангидрата получены цельные НЧ, описанные как «наногубки» (НГ). Полимер характеризуется биосовместимостью и способностью избирательно усваиваться клетками в ответ на изменение $\mathrm{pH}$. Доксорубицин хорошо упаковывается в наноструктуру и демонстрирует медленную и стабильную динамику высвобождения. Отмечено, что локальный уровень $\mathrm{pH}$ влияет на скорость вывода препарата. Сочетание $\mathrm{pH}$ специфичности и способности к пролонгированному высвобождению доксорибуцина в CNN-наноструктуре, их совместное усиленное противоопухолевое действие позволяют утверждать, что такие наноструктуры успешно работают в качестве инструмента наномедицины, демонстрируя при этом мягкий токсикологический просиль терапии [21].

Стоит отдельно отметить применение флуоресцентномеченых производных ЦД для рН-зависимого блокирования $\mathrm{SiO}_{2}$-мезопор, где также продемонстрирована благоприятная кинетика высвобождения доксорубицина. Подобная система предоставляет в распоряжение специалиста значительное преимущество благодаря возможности отслеживать перемещение флуоресцентно окрашенных НЧ в ходе терапии [22].

Таблица. Примеры биологически активных веществ в составе нанопузырьков

\begin{tabular}{|l|l|l|}
\hline \multicolumn{1}{|c|}{ Терапевтическое действие } & \multicolumn{1}{|c|}{ Лекарственный препарат } & \multicolumn{1}{c|}{ Способ введения } \\
\hline Противоопухолевое & Доксорубицин, паклитаксел, доцетаксел, цисплатин & Парентерально \\
\hline Антибактериальное & Ванкомицин, эритромицин & Местно \\
\hline Противогрибковое & Итраконазол & Местно \\
\hline Противовирусное & Ацикловир, валацикловир & Местно \\
\hline Противовоспалительное & Преднизолон & Парентерально \\
\hline Генная терапия & ДНК, малые интерферирующие PHK (siRNA) & Парентерально \\
\hline Патологии, связанные с гипоксией & Кислород & Парентерально / Местно \\
\hline Тераностические системы & Gd-комлексы & Парентерально \\
\hline Другое & Куркумин, мелатонин & Парентерально / Местно \\
\hline
\end{tabular}




\section{2. Наночастицы с редокс-зависимым ответом}

Разработка и создание НЧ с редокс-зависимым ответом еще одно перспективное направление в адресной доставке лекарственных препаратов к специфическим местам внутри клеток опухоли. В качестве опорной модели при создании редокс-зависимых наноносителей была выбрана функционирующая внутри раковой клетки и хорошо изученная система окисления глутатиона (GSH) Показано, что концентрация глутатиона, локализованного в опухолевых клетках, в 100-500 раз выше, чем в нормальных [23]. Известно также, что уровень GSH в межклеточном пространстве может провоцировать обмен связями в тиол-дисульфидной системе. Полимеры, имеющие в своей структуре дисульсидные связи, могут с успехом «эксплуатировать» данное свойство для быстрого высвобождения препарата при стимуляции глутатионом. В общем случае существует два пути использования особенностей дисульфидных связей в полимерных системах: а) модификацией дисульфидной связи непосредственно на каркасе полимера; б) посредством создания дисульфидных связей в качестве кросс-линкеров внутри полимерной сети.

В одном из исследований модифицировали систему доставки активного вещества, предложив использование наногубки, чувствительной $\mathrm{k}$ глутатиону и способной дестабилизироваться внутри клетки [24]. Дисульфидные связи полимера способны продолжительное время сохранять свою стабильность во внеклеточном пространстве, однако утрачивают ее, как только оказываются внутри клетки. Таким образом повышается биодоступность и эсфективность работы редокс-зависимой наносистемы, поскольку истощение источника эндогенных антиоксидантов, таких как глутатион, делает раковые клетки более восприимчивыми к химиотерапии. Результатом разработки стало появление нового класса глутатиончувствительных ЦД-наногубок (GSH-NS), предназначенных для целевой доставки доксорубицина в клетки с высоким содержанием GSH. Глутатионспецифические носители, нагруженные доксорубицином, ингибировали клоногенный рост, жизнеспособность клеток, активность комплекса ॥ топоизомеразы, и кроме того, при наблюдении в различных клеточных линиях индуцировали повреждение структуры ДНК в большей степени, чем при введении свободного лекарства. Стоит отметить, что применение данной системы позволило более эффективно ингибировать развитие опухоли простаты, чем при введении несвязанного лекарственного препарата, без повышения уровня токсичности, как было показано на ксенографтах [24]. Нагруженные доксорубицином GSH-наносистемы оказывают влияние на клеточную пролиферацию в дозах более низких, чем при использовании доксорубицина в свободной форме, что обеспечивает эффективность лечения и минимизацию побочного действия.

\section{2. Наносистемы, чувствительные к внешним стимулам}

\section{1. Наночастицы с фотозависимым ответом}

Высвобождение лекарственного препарата фотовозбуждаемыми наносистемами запускается воздействием света определенной длины волны от внешнего источника К сожалению, низкая проникающая способность света накладывает существенные ограничения на область применения таких систем. В фотоиндуцируемой системе лекарство может быть связано с носителем посредством фоторазрушаемой связи или за счет применения носителя, наделенного способностью менять свою структуру при специфической засветке. Так, эффект ИКфотозависимого сброса доксорубицина демонстрирует матрица, выполненная из полимеров лакто-когликолевой кислоты с нанесением золота [25]. Золотосодержащие наносистемы доставки лекарств в последнее время привлекают к себе повышенное внимание благодаря широте и гибкости достигаемых оптических характеристик, легкости производства, функциональности и хорошей биологической совместимости. Кроме того, такие Нч занимают особое место среди наноплатформ благодаря уникальной способности выступать в качестве объекта для локализованного плазмонного резонанса (SPR,

ЛПР) - метода, применяемого при мультимодальной терапии рака, в частности, при фототермальной терапии [26]. Под воздействием облучения в ближней ИК-области ЛПР в золотосодержащей НЧ приводит $\mathrm{K}$ локальному разогреву (на несколько градусов выше значения температуры тела). Подобную схему применяют, в частности, в нанокапсулах AutoShells для терапии очага опухоли, которые уже сегодня проходят стадию клинических испытаний. После внутривенного введения такие НЧ попадают под воздействие лазера, подведенного посредством оптического волокна, инициируют локальный разогрев в очаге раковой опухоли, обеспечивая тем самым фототермальную терапию [27]. Кроме того, поверхность золотонесущих НЧ пригодна для присоединения лекарственных веществ, олигонуклеотидов и пептидов. Данная наноплатформа может быть с успехом применена для выполнения задач по целевой доставке веществ и их высвобождению под воздействием внешнего сигнала.

\section{2. Наночастицы и нанопузырьки, чувствительные к температуре и УЗ}

Изменение температуры - один из удобных и эффективных факторов для контролирования высвобождения лекарственного препарата из наноносителя. При патофизиологических условиях, таких как опухолевые процессы, температура тканей выше температуры в здоровых тканях. Эта разница может выступать в качестве триггера, запуская процесс высвобождения лекарственного препарата в очаге опухоли. Термочувствительные наноносители разрабатывают таким образом, чтобы удерживать лекарственный агент при физиологической температуре $\left(37^{\circ} \mathrm{C}\right)$ и высвобождать его при повышении температуры до $40-45^{\circ} \mathrm{C}$. Из соображений безопасности диапазон температур для большинства наносистем рассчитывается таким образом, чтобы порог чувствительности к температурному сигналу превышал фоновые температурные флуктуации.

Специфическая аккумуляция лекарственного вещества в опухоли может быть достигнута совместным использованием эффекта гипертермии в присутствии термо-чувствительных липосом. ThermoDox - термозависимая липосомная наносистема - ближе других решений продвинулась на пути к клиническим исследованиям. Эта наносистема спроектирована таким образом, чтобы достигать кумулятивного эффекта от применения пассивного механизма высвобождения доксорубицина в опухолевой ткани совместно с повышением эффективности его доставки через микроциркуляторную часть сосудистого русла за счет использования внешнего источника нагрева, 
в частности УЗ. Температура плавления липидного кристалла дипалмитолфосфатидинхолина составляет $41,5{ }^{\circ} \mathrm{C}$, поэтому построенная на нем наносистема высвобождает доксорубицин, оказавшись в этих температурных условиях. Дополнительное действие на выброс лекарственного вещества в случае с ThermoDox оказывает УЗ-абляция. Результаты гепатотерапии с применением ThermoDox демонстрируют улучшенный токсикологический профиль в сравнении с традиционным протоколом введения лекарства, что было показано в ходе фазы I клинических испытаний. Несмотря на недостаточно высокий (33\%) показатель продолжительности жизни после применения ThermoDox, зафиксированный в фазе III клинических испытаний, общая стратегия применения данной системы в качестве стимул-зависимого средства доставки может оказаться перспективной [19].

\section{3. Наночастицы и нанопузырьки, чувствительные к УЗ}

В клинической диагностике и терапии УЗ широко применяют во многом благодаря высокой проникающей способности и безопасности для организма. Низкочастотный УЗ способен проникать в органы тела без значительного рассеяния на несколько сантиметров [18].

На ткани организма УЗ оказывает воздействие разными путями, в том числе посредством локального повышения температуры. Его влияние варьирует в зависимости от используемой частоты волны, интенсивности излучения и продолжительности воздействия. Локальный прогрев тканей с помощью УЗ широко применяют на практике (сфокусированный УЗ высокой интенсивности) при терапии рака простаты [28], в то время как терапевтическое использование нетермического воздействия УЗ изучено в меньшей степени. Помимо термоэффекта УЗ используют для: а) переключения проницаемости биологических барьеров (сонопорация); б) регулирования доставки лекарственных средств; в) в сонодинамической терапии. Последнее применение открывает новые возможности в терапии рака. Сонодинамическая терапия (СДТ) метод, при котором малотоксичная молекула или система (химический актуатор, соносенсибилизатор) активируется физическим воздействием УЗ, приводя к окислению, последующему повреждению и гибели злокачественной клетки. Эффект СДТ достигается за счет приложения внешнего стимула при наличии активируемой им молекулы или коллоидной системы. Комбинирование двух этих факторов в свою очередь обеспечивает биологический эффект. Акустическая кавитация формирование или функциональность полостных образований, наполненных газом или паром (пузырьков) в среде, подверженной воздействию УЗ. Различают два состояния акустической кавитации - стабильного, при котором совершаемые колебания приводят к испарению жидкости и активному перемешиванию окружающей их микросреды; и инерционного, при котором растущие полости увеличиваются до размеров, сопоставимых с длиной волны УЗ, а достигнув своего максимума, взрываются. Во втором случае при выбросе энергии температура микроокружения вокруг взрыва может резко вырастать до $10000{ }^{\circ} \mathrm{C}$, а давление - до $81 \mathrm{MПа,}$ превращая систему в своего рода «сонохимический реактор» [29]. При проведении противораковой СДТ НЧ могут выступать не только в качестве стимул-зависимого соносенсибилизированного средства транспортировки с улучшенными пространственными и скоростными характеристиками, но и, при грамотном дизайне, как соносенсибилизатор «сам в себе» [30].

Отдельный интерес представляет совместное использование нанопузырьков и УЗ для целевой доставки нуклеиновых кислот [31]. Техника доставки достигается за счет применения различных методик «загрузки», таких как прямое физическое «укладывание» молекулы ДНК внутрь транспортной капсулы в лабораторных условиях, применение в капсуле отрицательно заряженных липидов или полимеров, способных связывать молекулу ДНК электростатически, и, наконец, ковалентное связывание НЧ с цепью ДНК.

Нам представилась возможность использовать различные наносистемы и применять их как в качестве системы доставки в связке с УЗ-чувствительным химическим агентом (соносентитайзером), так и в качестве УЗ-зависимой системы «сам в себе» для СДТ рака. При этом была продемонстрирована значительная противораковая активность цельнотельных Н4 из полиметилметакрилата, нагруженных мезотетракис(4сульфонатофенил)порфирином (ТPPS-PММАНЧ), при воздействии УЗ в целевом сайте в модели in vitro нейробластомы [32]. Эти НЧ были адаптированы для применения in vivo в соносенсибилизированных системах, в качестве радиометок и магнитно-резонансных агентов визуализации, что делало их пригодными для направленного лечения плотных опухолей и визуализации. Наносистему нагружали TPPS для проведения противораковой СДТ, либо ${ }^{64} \mathrm{Cu}$-TPPS для использования в исследовании топографии распространения при помощи позитронэмиссионной томограсрии или же Mn(III)-TPPS для изучения методом магнитного резонанса. По результату сравнения данных МР-исследования для материала, взятого до и после лечения в сингенной модели рака груди, наносистема TPPS-PMМАНЧ демонстрировала чувствительность к УЗ, свидетельствуя о том, что данная мультимодальная система может с успехом применяться в качестве селективного управляемого извне инструмента в борьбе с раком [33].

Были также изучены свойства неорганических НЧ, в данном случае из золота, с целью лучше понять уникальность свойственного им феномена ЛПР. Золотые HЧ, соединенные с фолатполиэтиленгликолем (FAPEG-GH4), были подвергнуты испытанию в качестве соносенсибилизатора в лечении рака. Чувствительность к УЗ-воздействию изучали на клеточной линии человеческих раковых клеток с различным количеством фолат-рецепторов. Было обнаружено, что FA-PEG-GH4 имеет селективную чувствительность к фолат-рецепторам гиперэкспрессивных раковых клеток, приводя через воздействие УЗ к снижению показателя клеточного роста, ощутимому приросту в генерации активных форм кислорода и увеличению количества некротических клеток [34]. Синергия использования целевой точности, характерной для НЧ из золота, с сенсибилизирующим эффектом, получаемым за счет местного внешнего стимула, делает эти наносистемы многообещающей платформой для сайт-специсической терапии рака. Данное исследование in vitro можно рассматривать как доказательство возможности применения золотых НЧ в лечении рака.

Понятие «нанопузырек» до момента приложения внешнего стимула, такого как УЗ, следует воспринимать скорее в значении «нанокапля», основа которой состоит из перфлюоропентана - перфлюорокарбона, находящегося 
В жидком состоянии при комнатной температуре (точка кипения равна $\left.29{ }^{\circ} \mathrm{C}\right)$. Высвобождение может быть активировано под воздействием УЗ за счет механизма акустической капельной вапоризации [35].

В одной из работ изучали целесообразность совместного применения нанопузырьков с УЗвоздействием при местном лечении кожных заболеваний. Был разработан носитель для лечения локальных кожных патологий, связанных с гипоксией, и ускорения процесса заживления ран [36].

Специально для доставки кислорода были разработань нанопузырьки с декстрановой и хитозановой оболочкой, нагруженные декафлуоропентаном («нанокапли») или додекафлуоропентаном («нанопузырьки»), которые за счет свойств перфлуорокарбоната были способны солюбилизировать и сохранять кислород в своем ядре, а также медленно и стабильно его высвобождать [36-39]. Декафлуоропентановая система продемонстрировала значительную эффективность при доставке кислорода в зоны гипоксии, в условиях как in vitro, так и in vivo, что было показано в ходе сравнительного анализа с применением оксиметрии и фотоакустической визуализации. Нанокапли в хитозановой оболочке, нагруженные кислородом, были предложены в качестве инновационного инструмента для адъювантной терапии при лечении заражений у больных с хроническими кожным болезнями за счет использования противомикробных свойств хитозана [36, 40].

Нагруженные кислородом нанокапли продемонстрировали высокую цитостатическую активность против метицилинустойчивых микроорганизмов Staphylococcus aureus (MRSA) и Candida albicans и не имели токсического эфффекта в человеческих кератиноцитах (НаСаT). Кроме того, дополнительное воздействие УЗ способствовало трансдермальной доставке кислорода из нанокапель в ткани, подверженные гипоксии. Исследования последних лет были посвящены глубокому изучению морфологии нанопузырьков, способствующих переносу кислорода, так как экзогенное поступление кислорода в опухоль затруднено в случае удаления от кровеносного русла. Хорошая растворимость кислорода в пузырьках дает преимущество при доставке кислорода в гипоксическую ткань.

Для целевой доставки лекарства при кожных инфекционных заболеваниях были спроектированы нанопузырьки, выполненные из декстрансульфата и нагруженные ванкомицином [41]. Совместное применение целевой доставки и воздействия УЗ способствовало проникновению антибиотика сквозь толщу кожного покрова за счет эффекта сонофореза, при этом целевое высвобождение лекарства происходило в очаге заболевания.

Были предложены нанопузырьки из диэтиламиноэтилдекстрана (DEAE), обеспечивающие защиту от воздействия протеаз и транспортировку нагруженных в них молекул ДНК для осуществления трансфекции плазмидной ДНК через клеточную мембрану. Цитотоксического эфффекта при этом не наблюдали [42]. Для транспортировки ДНК была предложена еще одна формула нанопузырьков на основе хитозана. Нанопузырьки с нагруженной в них ДНК имели размер до 300 нм, вмещая при этом значительный объем ДНК [43]. Были также проведены эксперименты с трансфекцией in vitro, в которых адгезивные клетки линии COS7 подвергали воздействию УЗ с частотой 2,5 МГц в присутствии различных концентраций нанопузырьков, заполненных плазмидной ДНК. Во всех протестированных концентрациях ни одна из трансфекций не прошла успешно без УЗ-стимула. В результате 30-секундного УЗвоздействия выявлялся умеренный процент успешной трансфекции. Исследования по оценке жизнеспособности клеток продемонстрировали, что ни УЗ, ни нанопузырьки не оказывали негативного влияния на систему в условиях проведенных экспериментов.

Постоянные усилия исследователей в области иммунотерапии рака в последние годы привели к появлению нескольких концепций вакцинации, основанных на опухолеассоциированных антигенах, таких как онкоген HER2.

Противораковая вакцинация имеет ряд очевидных преимуществ по сравнениию со стандартной терапией. Это и более высокая специфичность, и меньшая токсичность, и более мягкие долгосрочные эффекты, вызванные иммунной памятью. В этом смысле нанотехнологии обладают большим потенциалом для иммунотерапии и могут значительно улучшить ее качество. Ведь для качественного усиления иммунного ответа на развитие опухоли вакцина должна прежде всего достичь соответствующих дендритных клеток, играющих критическую роль в индуцировании корректной иммунной реакции.

В последние годы для лечения HER2-положительного рака груди был разработан новейший иммунотерапевтический инструмент - хитозановые нанопузырьки, несущие ДНК-вакцину и снабженные поверхностными антителами anti-CD11C для целевого распознавания дендритных клеток [44]. Подкожная инъекция нанопузырьков с CD11с, нагруженных pHER2, проявлялась в миграции дермальных дендритных клеток к дренированным лимфатическим узлам и замедлению роста HER2-положительной опухоли. Таким образом, в данном исследовании на модели с мышами наблюдали индуцированный клеточный и гуморальный иммунный ответ.

Исследователи изучают различные модисиикации нанопузырьков в качестве диагностико-терапевтических платформ, надеясь использовать их эхогенные свойства. Полимерный нанопузырек рассматривают в качестве многофункционального инструмента для целевой атаки на раковые клетки, УЗ-визуализации и для проведения УЗстимулируемой терапии рака.

Нами был разработан вариант хитозиновых нанопузырьков для использования в качестве диагностико-терапевтической системы, способной обеспечить двойную визуальную детекцию нанопузырьков [45]. Вариант наносистемы одновременно доставлял фоссрат преднизолона, размещенного на переднем крае перфлуоропентанного ядра, и отрицательно заряженный комплекс GD-DOTP, связанный электростатически с катионным хитозановым корпусом. Нанопузырьки проявляли свойство эхогенности, что позволяет использовать их в визуальных системах реального времени, и одновременно демонстрировали позитивный контраст в магнитнорезонансном исследовании.

Было изучено влияние экстракорпоральных ударных волн (ЭУВ) в качестве еще одного внешнего стимула, в результате реакции на который (помимо УЗ) может быть произведен выброс активного компонента наносистемы. ЭУВ короткоживущие (менее 10 мс) сфокусированные акустические колебания, широко применяемые в урологии для проведения литотрипсии и лечения различных опорнодвигательных дисфункций. Эффективность применения ЭУВ-стимулируемого нанотранспортного пузырька была 
детально изучена. Стоит заметить, что эффективность совместного действия нанопузырьков и ЭУВ изучали в отношении по меньшей мере двух агрессивных типов рака - анапластического рака щитовидной железы и рака простаты [46-49]. Согласно полученным данным, совместная терапия с использованием нанопузырьков, нагруженных паклитакселом или доцетакселом, и ЭУВ увеличивает цитотоксичность обоих лекарственных средств в двух линиях раковых клеток простаты (РС3 и DU145). В результате исследования дозировка паклитаксела Gl50 была уменьшена до 55\% от номинала, а доцетаксела - до 45\% (рис. 2) [48].

\section{4. Магнитные наночастицы}

Использование магнитных Н4 делает возможным неинвазивный пространственно-временной контроль процесса адресного переноса лекарственных препаратов и программируемого высвобождения препарата под воздействием внешнего магнитного поля. Чаще всего используемые магнитные НЧ обличаются рядом уникальных магнитных свойств. Большое соотношение поверхности к объему дает огромные возможности для конъюгации с биомолекулами, облегчая таким образом дизайн и разработку, чтобы намеченные «умные» способности таких НЧ (длительно циркулировать в кровотоке и адресно взаимодействовать с тканями) эффективно реализовывались при действии локализованного внешнего магнитного поля. Повышение температуры может быть вызвано разными источниками энергии, чаще всего применяется электромагнитная энергия. Гипертермию, как правило, вызывают высокими частотами (от 13 МГц до 430 МГц в зависимости от глубины опухоли) с использованием антенн с фазированной решеткой, помещаемых вне тела, в то время как частоты 915 МГц или 2,45 ГГц применяются для термоабляции с использованием внутритканевых антенн, помещенных в центр опухоли. Безопасность и эффективность гипертермии и термоабляции были показаны в нескольких клинических испытаниях [50]. Однако для обеих методик отмечены низкая воспроизводимость результатов, а также сложности с контролированием распределения температур внутри опухоли в различных клинических условиях. Проводимые в настоящее время исследования нацелены на увеличение однородности нагревания и специфичности взаимодействия с мишенью, минимизируя при этом инвазивность. Многообещающим способом решения этих задач может стать термолечение с помощью магнитных НЧ, Включающее локальное нагревание после инъекции НЧ в ткань и последовательное воздействие внешних магнитных полей. Основным ограничением магнитной термотерапии является низкая эффективность
A

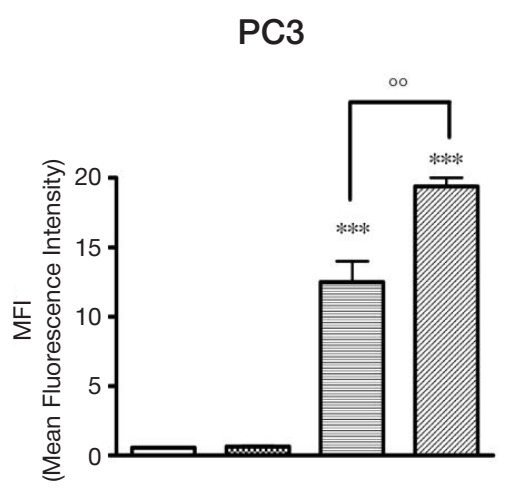

B

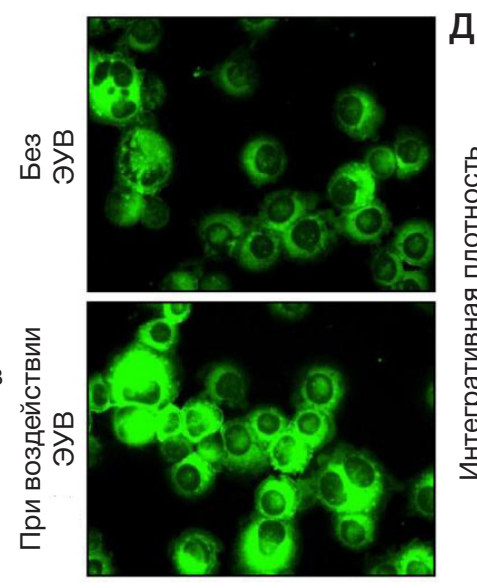

म

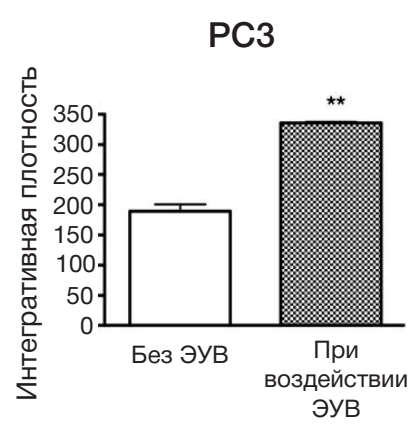

Б

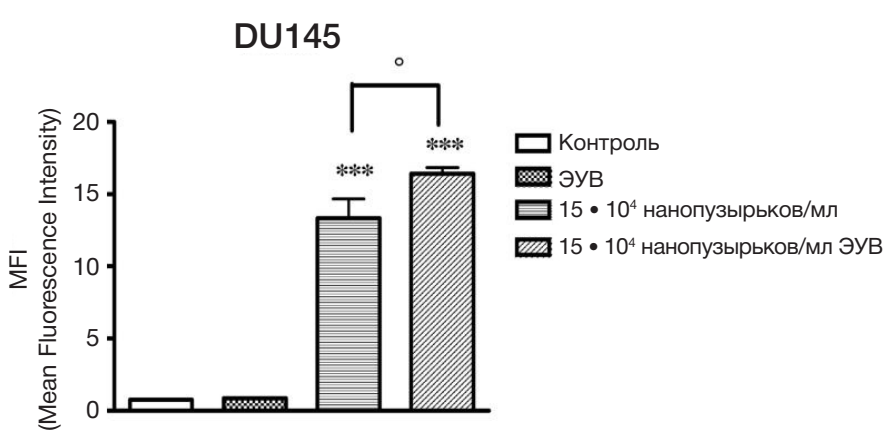

$\Gamma$

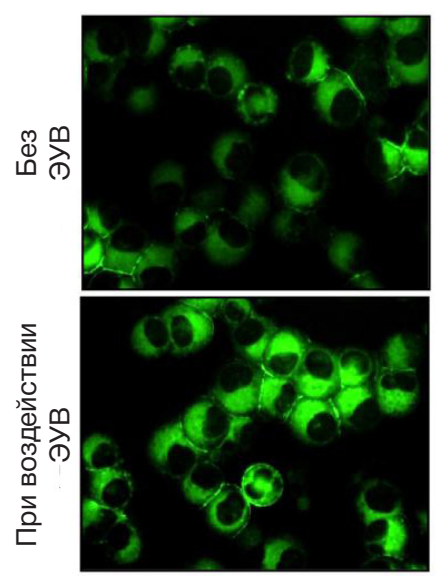

E

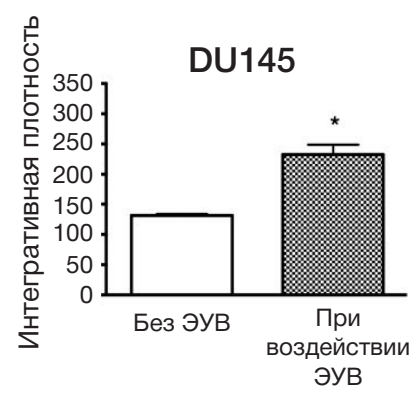

Рис. 2. Вход нанопузырька. Цитослуориметрический анализ клеточной линии PC3 (A) и DU145 (Б) через 24 ч после введения 6-кумарин-меченых гликольхитозиновых нанопузырьков (15 • 104 нанопузырьков/мл) либо при отсутствии или при использовании ЭУВ, выраженных в единицах средней

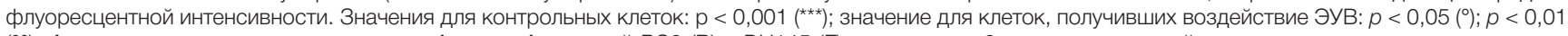
$\left({ }^{\circ}\right)$. Флуоресцентно-микроскопические фотографии линий PC3 (В) и DU145 (Г), получивших 6-кумарин-меченный гликольхитозановых нанопузырьков (15 • 104 нанопузырьков/мл). Показаны клетки при отсутствии и при воздействии ЭУВ. Увеличение ×200 (масштаб 100 мкм). Фотографии демонстрируют результаты трех независимых экспериментов. Произведен обсчет на 10 полях. Обсчет 6-кумарин-меченных гликольхитозановых нанопузырьков в клеточной

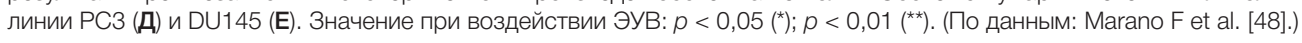


нагревания большинства магнитных наноматериалов, что приводит к тому, что терапевтический эффект наблюдается только при условии введения в опухоль больших количеств магнитных НЧ. В связи с этим основные усилия направлены, соответственно, на оптимизацию эффективности нагревания и биосовместимости, путем подбора размеров частиц с учетом их физических свойств, а также различных материалов покрытия. Разработанные недавно магнитные нанодиски и нанокольца могут стать альтернативой магнитным НЧ, поскольку характеризуются незначительным остаточным намагничиванием и последовательным ослаблением дальнодействующих магнитостатических сил, ответственных за агломерацию частиц. Предварительные исследования продемонстрировали потенциал этих наноструктур как эффеективных нанопосредников в термотерапии рака, поскольку они показывают улучшенные характеристики гипертермии относительно изотропных магнитных частиц. Магнитные частицы Ni80Fe20 в форме диска были получены с помощью субмикронной литографии и непосредственно покрыты слоем золота [51]. Авторами была проведена функционализация золотой поверхности частиц цистеинпроизводным фллуоресцеинизотиоцианата (ФИТЦ), чтобы вызвать случайную флуоресценцию для использования в качестве средства оценки попадания внутрь клеток. Процесс намагничивания частиц характеризовался присутствием «завихрений», указывающих на возможную задействованность в процессе доставки лекарственных средств и также при магнитной гипертермии. Стоит отметить, что тесты на цитотоксичность показали более высокую биосовместимость не полностью покрытых золотом частиц по сравнению с непокрытыми нанодисками. Накопление магнитных НЧ в клетках было подтверждено цитофлуорометрически, с использованием конъюгата ФИТЦ на поверхности покрытых золотом частиц [52].

\section{ВЫВОДЫ}

Использование в биомедицине «умных» систем адресной доставки лекарственных средств с помощью НЧ оказалось весьма высокоэффективным. Однако до перехода к клиническим испытаниям требуется тщательная всесторонняя оценка их терапевтического потенциала. Ряд стимулчувствительных наносистем в настоящее время проходят клиническую оценку, но пока лишь несколько из них, в частности NanoTherms ${ }^{\circledR}$, были одобрены для клинического применения, при этом большинство коммерциализировано для использования в научных исследованиях [18]. Будущие исследования в области наносистем адресной доставки лекарственных препаратов должны быть сосредоточены на разработке более легко осуществимых на практике и однотипных методов получения наноносителей, а также переходе к клиническому применению с целью внедрения данных методик в практическое использование. Важнейшей задачей для исследователей в настоящее время является проведение тщательных доклинических испытаний перспективных наносистем с целью улучшения воспроизводимости результатов и последующим переходом к клиническим испытаниям.

\section{Литература}

1. Portehault D, Delacroix S, Gouget G, Grosjean R, Chan-Chang T-H-C Beyond the Compositional Threshold of Nanoparticle-Based Materials. Accounts of Chemical Research. 2018; 51 (4): 930-9.

2. Cravotto $G$, Boffa $L$. Preparation of nanomaterials under combined ultrasound/microwave irradiation. Pan Stanford Publishing Pte. Ltd.: 2014; p. 203-26.

3. Martina K, Tagliapietra S, Barge A, Cravotto G. Combined Microwaves/Ultrasound, a Hybrid Technology. Top Curr Chem. 2016; 374 (6): 1-27.

4. Davis ME, Brewster ME. Cyclodextrin-based pharmaceutics: past, present and future. Nat Rev Drug Discov. 2004; (3): 1023-35.

5. Barge A, Caporaso M, Cravotto G, Martina K, Tosco P, Aime S et al. Design and Synthesis of a $\gamma 1 \beta 8$-Cyclodextrin Oligomer: A New Platform with Potential Application as a Dendrimeric Multicarrier. Chem Eur J. 2013; 19 (36): 12086-92.

6. Martina K, Baricco F, Berlier G, Caporaso M, Cravotto G. Efficient Green Protocols for Preparation of Highly Functionalized B-Cyclodextrin-Grafted Silica. ACS Sustainable Chem Eng. 2014 2 (11): 2595-603.

7. Huq R, Mercier L, Kooyman PJ. Incorporation of Cyclodextrin into Mesostructured Silica. Chem Mater. 2001; 13 (12): 4512-9.

8. Lee J-H, Kang S, Ahn M, Jang H, Min D-H. Development of dualpore coexisting branched silica nanoparticles for efficient genechemo cancer therapy. Small. 2018; 14 (7): 1702564.

9. Calcio Gaudino E, Tagliapietra S, Martina K, et al. Novel SWCNT platform bearing DOTA and $\beta$-cyclodextrin units. "One shot" multidecoration under microwave irradiation. Org Biomol Chem. 2014; (12): 4708-15.

10. Bosca F, Orio L, Tagliapietra S, Corazzari I, TurciF, Martina K, Pastero L, Cravotto G et al. Microwave-Assisted Synthesis and Physicochemical Characterization of TetrafuranylporphyrinGrafted Reduced-Graphene Oxide. Chem Eur J. 2016; (22): 1608-13.

11. Duan S, Li J, Zhao N, Xu F-J. Multifunctional hybrids with versatile

types of nanoparticles via self-assembly for complementary tumor therapy. Nanoscale. 2018; (10): 7649-57.

12. Bolden NW, Rangari VK, Jeelani S, Boyoglu S, Singh SR. Synthesis and evaluation of magnetic nanoparticles for biomedical applications. J Nanopart. 2013: 1-9; DOI:10.1155/2013/370812.

13. Güvener N, Appold L, de Lorenzi F, Golombek SK, Rizzo LY, Lammers T, Kiessling F. Recent advances in ultrasoundbased diagnosis and therapy with micro-and nanometer-sized formulations. Methods. 2017; (130): 4-13.

14. Cavalli R, Soster M, Argenziano M. Nanobubbles: a promising efficient tool for therapeutic delivery. Ther Deliv. 2016; 7 (2): 117-38.

15. Delalande A, Postema M, Mignet N, Midoux P, Pichon C. Ultrasound and microbubble-assisted gene delivery: recent advances and ongoing challenges. Ther Deliv. 2012; 3 (10): 1199-215.

16. Cavalli R, Bisazza A, Giustetto P, Civra A, Lembo D, Trotta G et al. Preparation and characterization of dextran nanobubbles for oxygen delivery. Int J Pharm. 2009; 381 (2): 160-5.

17. Malam Y, Loizidou M, Seifalian AM. Liposomes and nanoparticles: nanosized vehicles for drug delivery in cancer. Trends Pharmacol Sci. 2009 Nov; 30 (11): 592-9.

18. Alvarez-Lorenzo C1, Concheiro A. Smart drug delivery systems: from fundamentals to the clinic. Chem Commun. 2014; 50 (58): 7743-65.

19. Liu D, Yang F, Xiong F, Gu N. The Smart Drug Delivery System and Its Clinical Potential. Theranostics. 2016 Jun 7; 6 (9): 1306-23.

20. Sharifi S, Behzadi S, Laurent S, Forrest ML, Stroeve P, Mahmoudi M. Toxicity of nanomaterials. Chem Soc Rev. 2012 Mar 21; 41 (6): 2323-43.

21. Caldera F, Argenziano M, Trotta F, Dianzani C, Gigliotti L, Tannous M et al. Cyclic nigerosyl-1,6-nigerose-based nanosponges: An innovative $\mathrm{pH}$ and time-controlled nanocarrier for improving cancer treatment. Carbohydr Polym. 2018; (194): 111-21.

22. Chen X, Yao X, Wang C, Chen L, Chen X. Mesoporous silica 
nanoparticles capped with fluorescence-conjugated cyclodextrin for $\mathrm{pH}$-activated controlled drug delivery and imaging. Microporous Mesoporous Mater. 2015; (217): 46-53.

23. Torchilin VP. Multifunctional, stimuli-sensitive nanoparticulate systems for drug delivery. Nat Rev Drug Discov. 2014 Nov; 13 (11): 813-27.

24. Daga M, Ullio C, Argenziano M, Dianzani C, Cavalli R, Trotta F et al. GSH-targeted nanosponges increase doxorubicin-induced toxicity "in vitro" and "in vivo" in cancer cells with high antioxidant defenses. Free Radic Biol Med. 2016; (97): 24-37.

25. Yang J, Lee J, Kang J, Oh SJ, Ko HJ, Son JH et al. Smart drug-loaded polymer gold nanoshells for systemic and localized therapy of human epithelial cancer. Adv Mater. 2009 Nov 20; 21 (43): 4339-42.

26. Shukla R, Bansal V, Chaudhary M, Basu A, Bhonde RR, Sastry M. Biocompatibility of gold nanoparticles and their endocytotic fate inside the cellular compartment: a microscopic overview. Langmuir. 2005 Nov 8; 21 (23): 10644-54.

27. Schwartz JA, Shetty AM, Price RE, Stafford RJ, Wang JC, Uthamanthil RK et al. Feasibility study of particle-assisted laser ablation of brain tumors in orthotopic canine model. Cancer Res. 2009 Feb 15; 69 (4): 1659-67.

28. Maloney E, Hwang JH. Emerging HIFU applications in cancer therapy. Int J Hyperthermia. 2015; 31 (3): 302-9.

29. Giuntini F, Foglietta F, Marucco AM, Troia A, Dezhkunov NV, Pozzoli A et al. Insight into ultrasound-mediated reactive oxygen species generation by various metal-porphyrin complexes. Free Radic Biol Med. 2018; (121): 190-201.

30. Serpe L, Foglietta F, Canaparo R. Nanosonotechnology: The next challenge in cancer sonodynamic therapy. Nanotechnology Reviews. 2012; 1 (2): 173-82.

31. Cavalli R, Bisazza A, Lembo D. Micro-and nanobubbles: a versatile non-viral platform for gene delivery. Int J Pharm. 2013; 456 (2): 437-45.

32. Canaparo R, Varchi G, Ballestri M, Foglietta F, Sotgiu G, Guerrini A et al. Polymeric nanoparticles enhance the sonodynamic activity of meso-tetrakis (4-sulfonatophenyl) porphyrin in an in vitro neuroblastoma model. Int J Nanomedicine. 2013; (8): 4247-63.

33. Varchi G, Foglietta F, Canaparo R, Ballestri M, Arena F, Sotgiu G et al. Engineered porphyrin loaded core-shell nanoparticles for selective sonodynamic anticancer treatment. Nanomedicine 2015; 10 (23): 3483-94.

34. Brazzale C, Canaparo R, Racca L, Foglietta F, Durando G, Fantozzi $R$ et al. Enhanced selective sonosensitizing efficacy of ultrasound-based anticancer treatment by targeted gold nanoparticles. Nanomedicine. 2016; 11 (23): 3053-70.

35. Kripfgans OD, Fowlkes JB, Miller DL Eldevik OP, Carson PL. Acoustic droplet vaporization for therapeutic and diagnostic applications. Ultrasound Med Biol. 2000; 6 (7): 1177-89.

36. Prato M, Magnetto C, Jose J, Khadjavi A, Cavallo F, Quaglino E et al. $2 \mathrm{H}, 3 \mathrm{H}$-decafluoropentane-based nanodroplets: new perspectives for oxygen delivery to hypoxic cutaneous tissues. PLoS One. 2015; 10 (3): e0119769.

37. Basilico N, Magnetto C, D'Alessandro S, Panariti A, Rivolta I, Genova $\mathrm{T}$ et al. Dextran-shelled oxygen-loaded nanodroplets reestablish a normoxia-like pro-angiogenic phenotype and behavior in hypoxic human dermal microvascular endothelium, Toxicol Appl Pharmacol. 2015; 288 (3): 330-8.

\section{References}

1. Portehault D, Delacroix S, Gouget G, Grosjean R, Chan-Chang T-H-C Beyond the Compositional Threshold of Nanoparticle-Based Materials. Accounts of Chemical Research. 2018; 51 (4): 930-9.

2. Cravotto G, Boffa L. Preparation of nanomaterials under combined ultrasound/microwave irradiation. Pan Stanford Publishing Pte. Ltd.: 2014; p. 203-26.

3. Martina K, Tagliapietra S, Barge A, Cravotto G. Combined Microwaves/Ultrasound, a Hybrid Technology. Top Curr Chem. 2016; 374 (6): 1-27.

4. Davis ME, Brewster ME. Cyclodextrin-based pharmaceutics:
38. Cavalli R, Bisazza A, Rolfo A, Balbis S, Madonnaripa D, Caniggia I et al. Ultrasound-mediated oxygen delivery from chitosan nanobubbles. Int J Pharm. 2009; 378 (1-2): 215-7.

39. Khadjavi A, Magnetto C, Panariti A, Argenziano M, Gulino GR, Rivolta I et al. Chitosan-shelled oxygen-loaded nanodroplets abrogate hypoxia dysregulation of human keratinocyte gelatinases and inhibitors: new insights for chronic wound healing. Toxicol Appl Pharmacol. 2015; 286 (3): 198-206.

40. Banche G, Prato M, Magnetto C, Allizond V, Giribaldi G, Argenziano M et al. Antimicrobial chitosan nanodroplets: new insights for ultrasound-mediated adjuvant treatment of skin infection. Future Microbiol. 2015; 10 (6): 929-39.

41. Argenziano M, Banche G, Luganini A, Finesso N, Allizond V, Gulino GR et al. Vancomycin-loaded nanobubbles: A new platform for controlled antibiotic delivery against methicillinresistant Staphylococcus aureus infections. Int J Pharm. 2017; 523 (1): 176-88.

42. Bisazza A, Civra A, Donalisio M, Lembo D, Cavalli R. The in vitro characterization of dextran-based nanobubbles as possible DNA transfection agents. Soft Matter. 2011; 7 (22): 10590-3.

43. Cavalli R, Bisazza A, Trotta M, Argenziano M, Civra A, Donalisio M et al. New chitosan nanobubbles for ultrasound-mediated gene delivery: preparation and in vitro characterization. Int $J$ Nanomedicine. 2012; (7): 3309-18.

44. Cavalli R, Occhipinti S, Argenziano M, Bessone F, Guiot C, Giovarelli M. Nanobubble technology-based HER2 immunotherapy through dendritic cells targeting. Presented at "CRS Annual Meeting \& Exposition", July 16-19 2017; Boston, Massachusetts, USA.

45. Cavalli R, Argenziano M, Vigna E, Giustetto P, Torres E, Aime S et al. Preparation and in vitro characterization of chitosan nanobubbles as theranostic agents. Colloids Surf B Biointerfaces. 2015; (129): 39-46.

46. Marano F, Argenziano M, Frairia R, Adamini A, Bosco O, Rinella $L$ et al. Doxorubicin-loaded nanobubbles combined with extracorporeal shock waves: basis for a new drug delivery tool in anaplastic thyroid cancer. Thyroid. 2016; 26 (5): 705-16.

47. Marano F, Frairia R, Rinella L, Argenziano M, Bussolati B, Grange C et al. Combining doxorubicin-nanobubbles and shockwaves for anaplastic thyroid cancer treatment: preclinical study in a xenograft mouse model. Endocr Relat Cancer. 2017; 24 (6): 275-86.

48. Marano F, Rinella L, Argenziano M, Cavalli R, Sassi F, D'Amelio P et al. Targeting Taxanes to Castration-Resistant Prostate Cancer Cells by Nanobubbles and Extracorporeal Shock Waves. PloS One. 2016; 11 (12): e0168553.

49. Roberta C, Francesca M, Monica A, Alessandra V, Roberto F, Maria Graziella C. Combining Drug-Loaded Nanobubbles and Extracorporeal Shock Waves for Difficult-to-Treat Cancers. Current Drug Delivery. 2017; (14): 1-3.

50. Glazer ES, Curley SA. The ongoing history of thermal therapy for cancer. Surg Oncol Clin N Am. 2011; 20 (2): 229-35.

51. Kosiorek A, Kandulski W, Glaczynska H, Giersig M. Fabrication of nanoscale rings, dots, and rods by combining shadow nanosphere lithography and annealed polystyrene nanosphere masks. Small. 2005; (1): 439-44.

52. Barrera G, Serpe L, Celegato F, Coïsson M, Martina K, Canaparo R et al. Surface modification and cellular uptake evaluation of Aucoated Ni80Fe20 nanodiscs for biomedical applications. Interface Focus. 2016; 6 (6). DOI: 10.1098/rsfs.2016.0052.

past, present and future. Nat Rev Drug Discov. 2004; (3): 1023-35. 5. Barge A, Caporaso M, Cravotto G, Martina K, Tosco P, Aime S et al. Design and Synthesis of a $\gamma 1 \beta 8$-Cyclodextrin Oligomer: A New Platform with Potential Application as a Dendrimeric Multicarrier. Chem Eur J. 2013; 19 (36): 12086-92.

6. Martina K, Baricco F, Berlier G, Caporaso M, Cravotto G. Efficient Green Protocols for Preparation of Highly Functionalized $\beta$-Cyclodextrin-Grafted Silica. ACS Sustainable Chem Eng. 2014; 2 (11): 2595-603.

7. Huq R, Mercier L, Kooyman PJ. Incorporation of Cyclodextrin into 
Mesostructured Silica. Chem Mater. 2001; 13 (12): 4512-9.

8. Lee J-H, Kang S, Ahn M, Jang H, Min D-H. Development of dualpore coexisting branched silica nanoparticles for efficient genechemo cancer therapy. Small. 2018; 14 (7): 1702564.

9. Calcio Gaudino E, Tagliapietra S, Martina K, et al. Novel SWCNT platform bearing DOTA and $\beta$-cyclodextrin units. "One shot" multidecoration under microwave irradiation. Org Biomol Chem. 2014; (12): 4708-15.

10. Bosca F, Orio L, Tagliapietra S, Corazzari I, TurciF, Martina K, Pastero L, Cravotto G et al. Microwave-Assisted Synthesis and Physicochemical Characterization of TetrafuranylporphyrinGrafted Reduced-Graphene Oxide. Chem Eur J. 2016; (22): 1608-13.

11. Duan S, Li J, Zhao N, Xu F-J. Multifunctional hybrids with versatile types of nanoparticles via self-assembly for complementary tumor therapy. Nanoscale. 2018; (10): 7649-57.

12. Bolden NW, Rangari VK, Jeelani S, Boyoglu S, Singh SR Synthesis and evaluation of magnetic nanoparticles for biomedical applications. J Nanopart. 2013: 1-9; DOI:10.1155/2013/370812.

13. Güvener N, Appold L, de Lorenzi F, Golombek SK, Rizzo LY, Lammers T, Kiessling F. Recent advances in ultrasoundbased diagnosis and therapy with micro-and nanometer-sized formulations. Methods. 2017; (130): 4-13.

14. Cavalli R, Soster M, Argenziano M. Nanobubbles: a promising efficient tool for therapeutic delivery. Ther Deliv. 2016; 7 (2): 117-38.

15. Delalande A, Postema M, Mignet N, Midoux P, Pichon C. Ultrasound and microbubble-assisted gene delivery: recent advances and ongoing challenges. Ther Deliv. 2012; 3 (10): 1199-215

16. Cavalli R, Bisazza A, Giustetto P, Civra A, Lembo D, Trotta G et al. Preparation and characterization of dextran nanobubbles for oxygen delivery. Int J Pharm. 2009; 381 (2): 160-5.

17. Malam Y, Loizidou M, Seifalian AM. Liposomes and nanoparticles: nanosized vehicles for drug delivery in cancer. Trends Pharmacol Sci. 2009 Nov; 30 (11): 592-9.

18. Alvarez-Lorenzo C1, Concheiro A. Smart drug delivery systems: from fundamentals to the clinic. Chem Commun. 2014; 50 (58) 7743-65.

19. Liu D, Yang F, Xiong F, Gu N. The Smart Drug Delivery System and Its Clinical Potential. Theranostics. 2016 Jun 7; 6 (9): 1306-23.

20. Sharifi S, Behzadi S, Laurent S, Forrest ML, Stroeve P, Mahmoudi M Toxicity of nanomaterials. Chem Soc Rev. 2012 Mar 21; 41 (6): 2323-43.

21. Caldera F, Argenziano M, Trotta F, Dianzani C, Gigliotti L, Tannous M et al. Cyclic nigerosyl-1,6-nigerose-based nanosponges: An innovative $\mathrm{pH}$ and time-controlled nanocarrier for improving cancer treatment. Carbohydr Polym. 2018; (194): 111-21.

22. Chen X, Yao X, Wang C, Chen L, Chen X. Mesoporous silica nanoparticles capped with fluorescence-conjugated cyclodextrin for $\mathrm{pH}$-activated controlled drug delivery and imaging. Microporous Mesoporous Mater. 2015; (217): 46-53.

23. Torchilin VP. Multifunctional, stimuli-sensitive nanoparticulate systems for drug delivery. Nat Rev Drug Discov. 2014 Nov; 13 (11): 813-27.

24. Daga M, Ullio C, Argenziano M, Dianzani C, Cavalli R, Trotta F et al. GSH-targeted nanosponges increase doxorubicin-induced toxicity "in vitro" and "in vivo" in cancer cells with high antioxidant defenses. Free Radic Biol Med. 2016; (97): 24-37.

25. Yang J, Lee J, Kang J, Oh SJ, Ko HJ, Son JH et al. Smart drug-loaded polymer gold nanoshells for systemic and localized therapy of human epithelial cancer. Adv Mater. 2009 Nov 20; 21 (43): 4339-42

26. Shukla R, Bansal V, Chaudhary M, Basu A, Bhonde RR, Sastry M. Biocompatibility of gold nanoparticles and their endocytotic fate inside the cellular compartment: a microscopic overview. Langmuir. 2005 Nov 8; 21 (23): 10644-54.

27. Schwartz JA, Shetty AM, Price RE, Stafford RJ, Wang JC Uthamanthil RK et al. Feasibility study of particle-assisted laser ablation of brain tumors in orthotopic canine model. Cancer Res. 2009 Feb 15; 69 (4): 1659-67.

28. Maloney E, Hwang JH. Emerging HIFU applications in cancer therapy. Int J Hyperthermia. 2015; 31 (3): 302-9.

29. Giuntini F, Foglietta F, Marucco AM, Troia A, Dezhkunov NV
Pozzoli A et al. Insight into ultrasound-mediated reactive oxygen species generation by various metal-porphyrin complexes. Free Radic Biol Med. 2018; (121): 190-201.

30. Serpe L, Foglietta F, Canaparo R. Nanosonotechnology: The next challenge in cancer sonodynamic therapy. Nanotechnology Reviews. 2012; 1 (2): 173-82.

31. Cavalli R, Bisazza A, Lembo D. Micro-and nanobubbles: a versatile non-viral platform for gene delivery. Int J Pharm. 2013; 456 (2): 437-45.

32. Canaparo R, Varchi G, Ballestri M, Foglietta F, Sotgiu G, Guerrini A et al. Polymeric nanoparticles enhance the sonodynamic activity of meso-tetrakis (4-sulfonatophenyl) porphyrin in an in vitro neuroblastoma model. Int J Nanomedicine. 2013; (8): 4247-63.

33. Varchi G, Foglietta F, Canaparo R, Ballestri M, Arena F, Sotgiu G et al. Engineered porphyrin loaded core-shell nanoparticles for selective sonodynamic anticancer treatment. Nanomedicine 2015; 10 (23): 3483-94.

34. Brazzale C, Canaparo R, Racca L, Foglietta F, Durando G, Fantozzi $\mathrm{R}$ et al. Enhanced selective sonosensitizing efficacy of ultrasound-based anticancer treatment by targeted gold nanoparticles. Nanomedicine. 2016; 11 (23): 3053-70.

35. Kripfgans OD, Fowlkes JB, Miller DL Eldevik OP, Carson PL. Acoustic droplet vaporization for therapeutic and diagnostic applications. Ultrasound Med Biol. 2000; 6 (7): 1177-89.

36. Prato M, Magnetto C, Jose J, Khadjavi A, Cavallo F, Quaglino E et al. 2H, 3H-decafluoropentane-based nanodroplets: new perspectives for oxygen delivery to hypoxic cutaneous tissues. PLoS One. 2015; 10 (3): e0119769.

37. Basilico N, Magnetto C, D'Alessandro S, Panariti A, Rivolta I, Genova $T$ et al. Dextran-shelled oxygen-loaded nanodroplets reestablish a normoxia-like pro-angiogenic phenotype and behavior in hypoxic human dermal microvascular endothelium, Toxicol Appl Pharmacol. 2015; 288 (3): 330-8.

38. Cavalli R, Bisazza A, Rolfo A, Balbis S, Madonnaripa D, Caniggia I et al. Ultrasound-mediated oxygen delivery from chitosan nanobubbles. Int J Pharm. 2009; 378 (1-2): 215-7.

39. Khadjavi A, Magnetto C, Panariti A, Argenziano M, Gulino GR, Rivolta I et al. Chitosan-shelled oxygen-loaded nanodroplets abrogate hypoxia dysregulation of human keratinocyte gelatinases and inhibitors: new insights for chronic wound healing. Toxicol Appl Pharmacol. 2015; 286 (3): 198-206.

40. Banche G, Prato M, Magnetto C, Allizond V, Giribaldi G, Argenziano M et al. Antimicrobial chitosan nanodroplets: new insights for ultrasound-mediated adjuvant treatment of skin infection. Future Microbiol. 2015; 10 (6): 929-39.

41. Argenziano M, Banche G, Luganini A, Finesso N, Allizond V, Gulino GR et al. Vancomycin-loaded nanobubbles: A new platform for controlled antibiotic delivery against methicillinresistant Staphylococcus aureus infections. Int J Pharm. 2017; 523 (1): 176-88.

42. Bisazza A, Civra A, Donalisio M, Lembo D, Cavalli R. The in vitro characterization of dextran-based nanobubbles as possible DNA transfection agents. Soft Matter. 2011; 7 (22): 10590-3.

43. Cavalli R, Bisazza A, Trotta M, Argenziano M, Civra A, Donalisio M et al. New chitosan nanobubbles for ultrasound-mediated gene delivery: preparation and in vitro characterization. Int $J$ Nanomedicine. 2012; (7): 3309-18.

44. Cavalli R, Occhipinti S, Argenziano M, Bessone F, Guiot C, Giovarelli M. Nanobubble technology-based HER2 immunotherapy through dendritic cells targeting. Presented at "CRS Annual Meeting \& Exposition", July 16-19 2017; Boston, Massachusetts, USA.

45. Cavalli R, Argenziano M, Vigna E, Giustetto P, Torres E, Aime S et al. Preparation and in vitro characterization of chitosan nanobubbles as theranostic agents. Colloids Surf B Biointerfaces. 2015; (129): 39-46.

46. Marano F, Argenziano M, Frairia R, Adamini A, Bosco O, Rinella $L$ et al. Doxorubicin-loaded nanobubbles combined with extracorporeal shock waves: basis for a new drug delivery tool in anaplastic thyroid cancer. Thyroid. 2016; 26 (5): 705-16.

47. Marano F, Frairia R, Rinella L, Argenziano M, Bussolati B, Grange C et al. Combining doxorubicin-nanobubbles and shockwaves for anaplastic thyroid cancer treatment: preclinical study in a xenograft mouse model. Endocr Relat Cancer. 2017; 24 (6): 275-86. 
48. Marano F, Rinella L, Argenziano M, Cavalli R, Sassi F, D'Amelio P et al. Targeting Taxanes to Castration-Resistant Prostate Cancer Cells by Nanobubbles and Extracorporeal Shock Waves. PloS One. 2016; 11 (12): e0168553.

49. Roberta C, Francesca M, Monica A, Alessandra V, Roberto F, Maria Graziella C. Combining Drug-Loaded Nanobubbles and Extracorporeal Shock Waves for Difficult-to-Treat Cancers. Current Drug Delivery. 2017; (14): 1-3.

50. Glazer ES, Curley SA. The ongoing history of thermal therapy for cancer. Surg Oncol Clin N Am. 2011; 20 (2): 229-35.
51. Kosiorek A, Kandulski W, Glaczynska H, Giersig M. Fabrication of nanoscale rings, dots, and rods by combining shadow nanosphere lithography and annealed polystyrene nanosphere masks. Small. 2005; (1): 439-44.

52. Barrera G, Serpe L, Celegato F, Coïsson M, Martina K, Canaparo R et al. Surface modification and cellular uptake evaluation of Aucoated Ni80Fe20 nanodiscs for biomedical applications. Interface Focus. 2016; 6 (6). DOI: 10.1098/rsfs.2016.0052. 